ORIGINAL ARTICLE

\title{
High co-prevalence of genogroup $1 \pi$ virus and human papillomavirus is associated with poor clinical outcome of laryngeal carcinoma
}

\author{
G Szládek, A Juhász, G Kardos, K Szőke, T Major, I Sziklai, I Tar, I Márton, J Kónya, L Gergely, \\ K Szarka
}

J Clin Pathol 2005;58:402-405. doi: 10.1136/icp.2004.022103

See end of article for authors' affiliations

Correspondence to:

Ms G Szládek, Department of Medical Microbiology, University of Debrecen, Debrecen, PO Box 17, H 4012, Hungary; szladekgyorgyi@ hotmail.com

Accepted for publication 17 September 2004

\begin{abstract}
Background: The aetiology and factors leading to the progression of laryngeal cancer are still unclear. Although human papillomavirus (HPV) has been suggested to play a role, reports concerning the effect of HPV infection on tumour development are controversial. Recently, transfusion transmitted virus (TTV) was suggested to play a role in certain infections as a causative or coinfecting agent.

Aims: To investigate whether the development and progression of laryngeal squamous cell carcinoma is associated with coinfection with TTV and HPV.

Methods: The prevalence of TV and HPV was investigated using the polymerase chain reaction in tissue samples from 40 healthy individuals, 10 patients with recurrent papillomatosis, five patients with papillomatosis with malignant transformation, and 25 patients with laryngeal carcinoma. The obtained prevalence data were compared and analysed statistically.

Results: In the 11 patients with carcinoma who had metastasis or relapse there was a high rate of coinfection with genogroup 1 TTV and HPV (eight of 11), whereas in the 14 without tumour progression no coinfection was found. Coinfection was associated with significantly lower tumour free survival in patients with carcinoma $(p<0.001)$. Furthermore, four of five patients who had papillomatosis with malignant transformation were coinfected with genogroup 1 TTV and HPV.

Conclusions: Although the nature of cooperation between HPV and TV needs to be investigated further, coinfection with genogroup 1 TTV and HPV appears to be associated with poor clinical outcome in laryngeal cancer.
\end{abstract}

M alignancies of the upper aerodigestive tract have a particularly high incidence and mortality rate in Eastern Europe. ${ }^{1}$ The exact aetiology and the mechanisms of progression of these diseases are still unclear. Certain mucotropic types of human papillomavirus (HPV) were suggested to play a role in squamous cell carcinomas of this region ${ }^{2}$; however, the prevalence of HPV in these cancers varies widely (range, 3-85\%) among different studies, and the impact of HPV positivity on the outcome is also unclear. ${ }^{3-8}$ Other factors, such as alcohol consumption or smoking, probably play a role in the development of cancer of the upper aerodigestive tract, and malignant transformation is thought to be caused by a combination of multiple carcinogenic factors. Chemical or microbial agents were suggested to enhance the effect of HPV in the progression of these and other malignancies. ${ }^{9-11}$

\footnotetext{
"It has been suggested that TT virus is a coinfecting virus promoting the pathological effect of other infectious agents"
}

The transfusion transmitted virus (TTV) is ubiquitous and TTV DNA is present in various human samples, including saliva and oropharyngeal tissues, although its aetiological role in pathogenetic processes is still unclear. It has been suggested that TTV is a coinfecting virus promoting the pathological effect of other infectious agents. ${ }^{12-14}$ High genetic divergence of TTV raised the question of whether the different TTV genogroups have diverse pathogenic potentials..$^{13} 1516$
In our study, we investigated the possible relation between the presence of HPV and/or TTV in patients with squamous cell carcinoma of the larynx and the severity and outcome of the disease.

\section{MATERIALS AND METHODS \\ Participants}

Forty healthy individuals and 40 patients with primary tumours of the head and neck area were enrolled in our study. Ten patients had recurrent respiratory papillomatosis (mean age, 27.7 years; range, 3-71), whereas another five had recurrent laryngeal papillomatosis with dysplasia, which finally progressed to carcinoma (mean age, 55 years; range, 43-66). Twenty five patients suffered from squamous cell carcinoma of the larynx (mean age, 56.6 years; range, 43-71). Eleven of the 25 patients with carcinoma had metastasis or relapse after surgery (tumour progression), whereas the other 14 remained tumour free during follow up. Written informed consent and permission were collected from each individual.

Excised tissue from patients was collected during surgery, and samples for DNA extraction were taken from the centre of the lesions. Exfoliated buccal epithelial cells were collected from 40 healthy individuals. Samples were stored at $-20^{\circ} \mathrm{C}$. DNA was isolated by phenol/chloroform/isoamylalcohol extraction after proteinase $\mathrm{K}$ treatment of the samples.

Abbreviations: HPV, human papillomavirus; ORF, open reading frame; PCR, polymerase chain reaction; TTV, transfusion transmitted virus; UTR, untranslated region 
Table 1 Virological status of the different study groups

\begin{tabular}{|c|c|c|c|c|}
\hline Study group & $\begin{array}{l}\text { TV positive } \\
\text { (UTR-PCR) }\end{array}$ & $\begin{array}{l}\text { Genogroup } 1 \text { TTV positive } \\
\text { (ORF-PCR) }\end{array}$ & HPV positive & $\begin{array}{l}\text { Genogroup } 1 \text { TTV-HPV } \\
\text { coinfection }\end{array}$ \\
\hline Healthy individuals $(n=40)$ & $29(72.5 \%)$ & $2(5 \%)$ & $10(25 \%)$ & $1(2.5 \%)$ \\
\hline Laryngeal papillomatosis $(n=10)$ & $8(80 \%)$ & $2(20 \%)$ & $10(100 \%)$ & $2(20 \%)$ \\
\hline Papilloma with malignant transformation $(n=5)$ & $5(100 \%)$ & $5(100 \%)$ & $4(80 \%)$ & $4(80 \%)$ \\
\hline Squamous cell carcinoma $(n=25)$ & $22(88 \%)$ & $11(44 \%)$ & $12(48 \%)$ & $8(32 \%)$ \\
\hline Without tumour progression $(n=14)$ & $11(78.6 \%)$ & $3(21.4 \%)$ & $3(21.4 \%)$ & $0(0 \%)$ \\
\hline With tumour progression ${ }^{*}(n=11)$ & $11(100 \%)$ & $8(72.7 \%)$ & $9(81.8 \%)$ & $8(72.7 \%)$ \\
\hline
\end{tabular}

\section{PCR methods}

The presence of HPV was tested by a nested polymerase chain reaction (PCR) capable of detecting a wide range of HPV types. The first round, with primers MY09 (5'-CGTCCMARR GGAWACTGATC-3') and MYII (5'-GCMCAGGGWCATAAY AATGG-3'), was carried out in a final volume of $50 \mu \mathrm{l}$ containing $1 \times$ RedTaq PCR buffer, $100 \mu \mathrm{M}$ dNTP, 50 pmol of each primer, $1 \mathrm{U}$ of RedTaq polymerase (Sigma, Germany), and $2 \mu \mathrm{l}$ of the DNA sample. PCR was performed as follows: $95^{\circ} \mathrm{C}$ for two minutes, followed by 40 cycles of $96^{\circ} \mathrm{C}$ for 20 seconds, $50^{\circ} \mathrm{C}$ for five seconds, $52^{\circ} \mathrm{C}$ for 15 seconds, and $72^{\circ} \mathrm{C}$ for 90 seconds, with a final extension step of $72^{\circ} \mathrm{C}$ for two minutes. The nested round with primers GP5 (5'-TTTGTTAC TGTGGTAGATAC- $\left.3^{\prime}\right)$ and GP6 (5'-GAAAAATAAACTGTAAA TCA-3') was performed at $95^{\circ} \mathrm{C}$ for two minutes, followed by 35 cycles of $94^{\circ} \mathrm{C}$ for 60 seconds, $48^{\circ} \mathrm{C}$ for 90 seconds, and $72^{\circ} \mathrm{C} 90$ seconds, with a final extension step of $72^{\circ} \mathrm{C}$ for two minutes. ${ }^{5} \mathrm{HPV}$ typing was performed as described elsewhere and classified as high risk or low risk HPV. ${ }^{17}$

TTV DNA was detected by two independent PCR methods. One, specific for the untranslated region (UTR), is capable of recognising essentially all TTV genogroups, and uses the primers NG133 (5'-GTAAGTGCACTTCCGAATGGCTGAG-3') and NGI47 (5'-GCCAGTCCCGAGCCCGAATTGCC-3') for the first round and NG132 (5'-AGCCCGAATTGCCCCTTGAC-3') and NG134 (5'-AGTTTTCCACGCCCGTCCGCAC-3') for the nested round (UTR-PCR). The other PCR assay uses the primers NG059 (5'-ACAGACAGAGGAGAAGGCAACATG-3') and NG063 (5'-CTGGCATTTTACCATTCCAAAGT-3') for the first round and primers NG061 (5'-GGCAACATGYTRTGGAT AGACTGG-3') and NG063 for the nested round. These primers are derived from the open reading frame 1 (ORF1) region of the TTV genome (ORF-PCR) and are capable of detecting genogroup 1 TTV. Both PCR assays were performed as follows: the first round PCR contained $5 \mu \mathrm{l}$ of DNA extract and the second round $5 \mu \mathrm{l}$ of the product of the first round in a final volume of $25 \mu \mathrm{l}$ containing $10 \times$ PCR buffer, $1.5 \mathrm{mM}$ $\mathrm{MgCl}_{2}, 50 \mathrm{pmol}$ of each primer, $100 \mu \mathrm{M}$ dNTP, and $1 \mathrm{U}$ of RedTaq genomic DNA polymerase. The first and the nested PCR rounds were carried out at $95^{\circ} \mathrm{C}$ for 60 seconds, followed by 30 and 25 cycles, respectively, of $95^{\circ} \mathrm{C}$ for 30 seconds, $58^{\circ} \mathrm{C}$ for 60 seconds, and $72^{\circ} \mathrm{C}$ for 60 seconds, with a final extension at $72^{\circ} \mathrm{C}$ for four minutes..$^{18}$

\section{Statistical analysis}

All statistical tests were carried out with a confidence interval of $95 \%$. Prevalence data were analysed with Fisher's exact test. The Kaplan-Meier test was performed to analyse tumour free survival.

\section{RESULTS}

Table 1 summarises the prevalence data for HPV, TTV, genogroup 1 TTV, and coinfection with HPV and genogroup 1 TTV in the study populations. Table 2 provides details of the statistical comparison of viral prevalence between the different study groups. TTV positivity was high (table 1) using the PCR method capable of detecting essentially all TTV genogroups (UTR-PCR). Because UTR-PCR positivity was similar in all comparisons (data not shown), further analyses were focused on genogroup 1 TTV positive cases.

\section{Patients with recurrent papillomatosis}

Papillomas excised from patients showed the characteristic histological signs of HPV infection. Exclusively low risk HPV types were found in all 10 patients.

\section{Patients with papillomatosis progressing to malignant transformation}

The initial histological diagnosis was papillomatosis with dysplasia in each case. Virological status was determined after histological evidence of malignant transformation. All five patients were positive for genogroup I TTV, and four were also HPV positive (two low risk HPV, two high risk $\mathrm{HPV}$ ), so the rate of coinfection was the highest in this group. Because of the small sample number, statistical comparison was not performed.

\section{Patients with squamous cell carcinoma}

Both low risk and high risk HPV types were detected in this group (in eight and four cases, respectively). The distribution of low risk and high risk HPV genotypes did not differ between patients with and without tumour progression. A significantly higher prevalence of HPV, genogroup 1 TTV, and coinfection was found in patients with tumour progression than in the healthy population or in patients without tumour progression (table 2). There were no significant differences between these prevalences when patients without tumour progression were compared with healthy individuals.

\section{Effect of genogroup 1 TTV and HPV coinfection on progression free survival}

Because the prevalence of coinfection was significantly higher in patients with tumour progression than in those without disease progression, we analysed the clinical outcome of disease in the 25 patients with cancer with regard to their virological status. We compared the progression free survival of patients without infection (10 of 25), those with single virus infection (seven of 25), and those with coinfection of genogroup 1 TTV and HPV (eight of 25). The progression free survival of patients without virus infection was not significantly different from that of those with single virus infection (Kaplan-Meier, $p=0.9571$ ). In addition, the progression free survival of patients without infection and with single virus infection was also significantly different from that of the patients with coinfection (Kaplan-Meier, $\mathrm{p}=0.0017, \mathrm{p}=0.0023$, respectively), allowing all patients without coinfection (17 of 25) to be compared as a group with those patients with coinfection (eight of 25). All eight coinfected patients, in contrast to only three of the 17 patients without coinfection, had metastasis or suffered a relapse. As shown in the Kaplan-Meier plot (fig 1), progression free survival was significantly worse in cases of 
Table 2 Statistical comparison of viral prevalences between the different study groups

\begin{tabular}{|c|c|c|c|c|}
\hline & $\begin{array}{l}\text { Laryngeal papillomatosis } \\
(n=10)\end{array}$ & Total SCC $(n=25)$ & $\begin{array}{l}\text { SCC without tumour } \\
\text { progression }(n=14)\end{array}$ & $\begin{array}{l}\text { SCC with tumour } \\
\text { progression* }(n=11)\end{array}$ \\
\hline $\begin{array}{l}\text { HPV prevalence } \\
\text { Healthy individuals }(n=40) \\
\text { Laryngeal papillomatosis }(n=10) \\
\text { SCC without tumour progression }(n=14)\end{array}$ & $p<0.001$ & $\begin{array}{l}N S \\
p=0.005\end{array}$ & $\begin{array}{l}\text { NS } \\
p<0.001\end{array}$ & $\begin{array}{l}p=0.001 \\
N S \\
p=0.005\end{array}$ \\
\hline $\begin{array}{l}\text { Genogroup } 1 \text { TV prevalence } \\
\text { Healthy individuals }(n=40) \\
\text { Laryngeal papillomatosis }(n=10) \\
\text { SCC without fumour progression }(n=14)\end{array}$ & NS & $\begin{array}{l}p<0.0001 \\
\text { NS }\end{array}$ & $\begin{array}{l}\text { NS } \\
\text { NS }\end{array}$ & $\begin{array}{l}p<0.0001 \\
p=0.03 \\
p=0.017\end{array}$ \\
\hline $\begin{array}{l}\text { Coinfection prevalence } \\
\text { Healthy individuals }(n=40) \\
\text { Laryngeal papillomatosis }(n=10) \\
\text { SCC without fumour progression }(n=14)\end{array}$ & NS & $\begin{array}{l}p=0.001 \\
N S\end{array}$ & $\begin{array}{l}\text { NS } \\
\text { NS }\end{array}$ & $\begin{array}{l}p<0.0001 \\
p=0.043 \\
p<0.001\end{array}$ \\
\hline
\end{tabular}

coinfection with genogroup 1 TTV and HPV than in the absence of coinfection $(\mathrm{p}<0.001)$.

\section{DISCUSSION}

Carcinomas of the laryngeal region are relatively frequent in the population and are associated with a high mortality. The aetiology of these cancers is unclear and several carcinogenetic factors have been implicated, including HPV infection'; however, the impact of HPV infection on tumour progression is still controversial. Recent reports have produced conflicting results: some have concluded that the presence of HPV alone has no influence on the outcome of the disease, ${ }^{68}$ others that HPV infected tumours have a better prognosis, ${ }^{7}$ and yet others have suggested that HPV infected tumours carry a worse prognosis than those with no detectable HPV. ${ }^{3}$ Because no clear connection could be shown between malignant head and neck tumours and HPV, a role for other co-carcinogenic agents was suggested. ${ }^{9}$

TTV was first isolated in 1997 from patients with hepatic failure $^{19}$; since then, despite many attempts, no clear evidence has been found to define TTV as a causative agent in disease. The high prevalence of TTV in healthy individuals suggests that most infections have no pathogenic importance; thus, it was proposed that certain genotypes might be more pathogenic than others or that TTV might play a role in accelerating the effects of other infectious agents. ${ }^{13} 162021$ Because TTV DNA is found in the oropharyngeal mucosa and saliva, ${ }^{14}$ it might also play a role in diseases of the upper aerodigestive tract.

We investigated the possible role of HPV and TTV infection in squamous cell carcinoma of the larynx. The total prevalence of TTV genogroups 1-5 was not significantly different between our study groups, and corresponds well

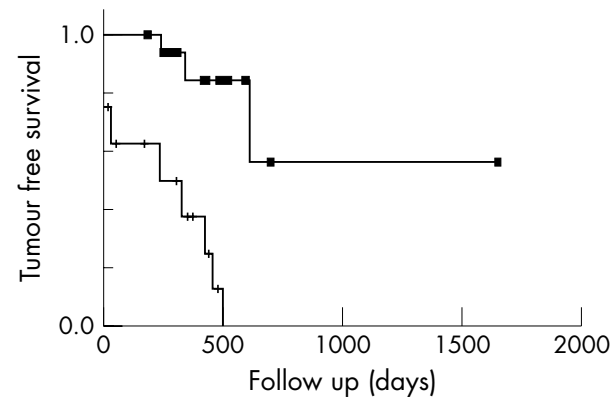

Figure 1 Effect of coinfection with human papillomavirus and genogroup 1 transfusion transmitted virus on tumour free survival of 25 patients with carcinoma (Kaplan-Meier test, $\mathrm{p}<0.001$ ); mean follow up time 400 days (range, $0-1651$ days). Squares, patients without coinfection; dashes, patients with coinfection. with that found in peripheral blood mononuclear cells of healthy donors from the same geographical area (95\%), as reported previously. ${ }^{22}$ The major findings of our study were the following: a prominent increase in the prevalence of genogroup 1 TTV in laryngeal cancer with progression $(72.7 \%)$ and significantly worse progression free survival of coinfected patients with cancer.

"It is our opinion that the high prevalence of genogroup 1 $\Pi T$ virus infection in patients with laryngeal cancer and its striking co-prevalence with human papillomavirus infection is biologically important in the progression of squamous cell carcinoma of the larynx"

There are several possible explanations for these findings, namely: (1) genogroup 1 TTV may have a tissue preference for certain laryngeal cell types, or for HPV infected tissues; (2) genogroup 1 TTV may have a preference for cells with an altered proliferation rate as a passenger virus; (3) there may be an interaction between genogroup 1 TTV and HPV, resulting in a tumour promoting effect via a yet undetermined mechanism.

(1) The prevalence values of genogroup 1 TTV in the samples of healthy individuals, in the patients with papillamatosis, and in patients with cancer without complication correspond well with the prevalence of genogroup 1 TTV in peripheral blood mononuclear cells of healthy blood donors from the same geographical area. ${ }^{22}{ }^{23}$ Thus, the increased prevalence of genogroup 1 TTV in patients with laryngeal cancer and tumour progression is unlikely to be caused by a preference for laryngeal tissue. The preferential infection of HPV infected cells with genogroup 1 TTV is also unlikely because there was no significant difference between the prevalence of genogroup 1 TTV in patients with papillomatosis and a 100\% HPV prevalence and the healthy population.

(2) The preferential infection of cells with an altered proliferation rate by genogroup I TTV can be excluded because, compared with healthy individuals, no significant difference was detected for genogroup l TTV prevalence in patients with papillomatosis or in those with laryngeal cancer without progression, although cells with abnormal proliferation were present in both these groups of patients.

(3) It is our opinion that the high prevalence of genogroup 1 TTV infection in patients with laryngeal cancer and its striking co-prevalence with HPV infection is biologically important in the progression of squamous cell carcinoma of the larynx. Interestingly, of our five cases of initial 


\section{Take home messages}

- Coinfection with genogroup 1 transfusion transmitted virus and human papillomavirus appears to promote the progression of squamous cell carcinoma of the larynx and is associated with an unfavourable outcome

- Further studies are needed to support this hypothesis and to elucidate the molecular mechanisms behind this presumed cooperation of viruses

papillomatosis with histological evidence of later malignant transformation, four were also positive for both viruses, supporting our hypothesis.

There are several possible explanations to account for the cooperation of genogroup 1 TTV and HPV. TTV has been proposed as a possible immune response modulator, ${ }^{24}$ so that genogroup 1 TTV infection may decrease the local immunoclearance of HPV infected cells with increased proliferation. Interaction of the two viruses may also occur if they infect the same cell, leading to alteration of host cell metabolic processes, modulation of HPV integration, alteration of antigen presentation pathways, increased expression of protooncogenes and/or cellular/viral antiapoptotic proteins.

In conclusion, our results suggest that coinfection with genogroup 1 TTV and HPV promotes the progression of squamous cell carcinoma of the larynx and is associated with an unfavourable prognosis. To support this hypothesis, prevalence studies on a wider selection of patients should be carried out in different countries, and the molecular mechanisms behind the presumed cooperation of viruses should also be investigated.

\section{ACKNOWLEDGEMENTS}

A Juhász was supported by ETT 116/2001 and Békésy Postdoctorial Fellowship 74/2002. J Kónya was supported by research grant OTKA T038416. L Gergely was supported by research grants OTKA T046608 and ETT 081/2003. K Szarka was supported by research grant OTKA F046479. The funding sources had no role in study design, data collection, data analysis, data interpretation, or writing of the article.

\section{Authors' affiliations}

G Szládek, Tumour Virus Research Group of the Hungarian Academy of Science, Debrecen, H 4012 Hungary

A Juhász, Department of Dermatology, University of Debrecen, H 4012, Debrecen, Hungary

G Kardos, K Szöke, J Kónya, L Gergely, K Szarka, Department of Medical Microbiology, University of Debrecen

T Major, I Sziklai, Clinic of Otorhinolaryngology and Head and Neck Surgery, University of Debrecen

I Tar, I Márton, Faculty of Dentistry, University of Debrecen

\section{REFERENCES}

1 Bray F, Sankila R, Ferlay J, et al. Estimates of cancer incidence and mortality in Europe in 1995. Eur $J$ Cancer 2002;38:99-166.

2 zur Hausen H. Papillomavirus infection-a major cause of human cancers. Biochem Biophys Acta 1996;1288:F55-78.

3 Clayman GI, Stewart MG, Weber RS, et al. Human papillomavirus in laryngeal and hypopharyngeal carcinomas. Arch Otolaryngol Head Neck Surg 1994;120:743-8.

4 Snijders P, van den Brule A, Meijer C, et al. HPV and cancer of the aerodigestive tract. Papillomavirus Report 1995;6:157-62.

5 Lindeberg H, Krogdahl A. Laryngeal cancer and human papillomavirus: HPV is absent in the majority of laryngeal carcinomas. Cancer Lett 1999; 146:9-13.

6 Pintos J, Franco EL, Black MJ, et al. Human papillomavirus and prognoses of patients with cancers of the upper aerodigestive tracts. Cancer 1999;85: 1903-9.

7 Ringström E, Peters E, Hasegawa M, et al. Human papillomavirus type 16 and squamous cell carcinoma of the head and neck. Clin Cancer Res 2002;8:3187-92.

8 Koskinen WJ, Chen RW, Leivo I, et al. Prevalence and physical status of human papillomavirus in squamous cell carcinomas of the head and neck. Int J Cancer 2003;107:401-6.

9 Sanderson RJ, Ironside JAD. Squamous cell carcinomas of the head and neck. BMJ 2002;325:822-7.

10 Koskela $\mathrm{P}$, Anttila T, Biorge T, et al. Chlamydia trachiomatis infection as a risk factor for invasive cervical cancer. Int J Cancer 2000;85:35-9.

11 Smith JS, Herrero R, Bosetti C, et al. Herpes simplex virus-2 as a human papillomavirus cofactor in the efiology of invasive cervical cancer. J Natl Cancer Inst 2002:94: 1604-13.

12 Okamoto H, Nishizawa T, Takahashi M, et al. Heterogeneous distribution of $\Pi$ virus of distinct genotypes in multiple tissues from infected humans. Virology 2001;288:358-68.

13 Maggi F, Marchi S, Fornai C, et al. Relationship of TT virus and Helicobacter pylori infection in gastric tissues of patients with gastritis. J Med Virol 2003;71:160-5.

14 Deng $X$, Terunuma $H$, Handema R, et al. Higher prevalence and viral load of $\Pi$ virus in saliva than in the corresponding serum: another possible route and replication site of TT virus. J Med Virol 1998;56:128-32.

15 Peng YH, Nishizawa T, Takahashi M, et al. Analysis of the entire genome of thirteen $T$ virus variants classifiable into the fourth and fifth genetic groups, isolated from viremic infants. Arch Virol 2002;147:21-41.

16 Okamura A, Yoshioka M, Kubota $M$, et al. Detection of a novel DNA virus (TTV) sequences in peripheral blood mononuclear cells. J Med Virol 1999;58:174-7.

17 Kónya J, Veress $G$, Juhász A, et al. Additional human papillomavirus types detected by the hybrid capture tube test among samples from women with cytological and colposcopical atypia. J Clin Microbiol 2000;38:408-11.

18 Okamoto H, Takahashi M, Nishizawa T, et al. Marked genomic heterogeneity and frequent mixed infection of $T$ virus demonstrated by PCR with primers from coding and noncoding regions. Virology 1999;259:428-36.

19 Nishizawa T, Okamoto H, Konishi K, et al. A novel DNA virus (TTV) associated with elevated transaminase levels in posttransfusion hepatitis of unknown etiology. Biochem Biophys Res Commun 1997;241:92-7.

20 Tokita H, Murai S, Kamitsukasa H, et al. High TT virus load as an independent factor associated with the occurrence of hepatocellular carcinoma among patients with hepatitis $C$ virus-related chronic liver disease. J Med Virol 2002:67:501-9.

21 Garbuglia AR, lezzi T, Capobianchi MR, et al. Detection of TT virus in lymph node biopsies of B-cell lymphoma and Hodgkin's disease, and its association with EBV infection. Int J Immunopathol Pharmacol 2003;16:109-18.

22 Szládek G, Juhász A, Asztalos L, et al. Persisting TT virus (TTV) genogroup 1 variants in renal transplant recipients. Arch Virol 2003;148:841-51.

23 Takács $M$, Balog $K$, Tóth $G$, et al. $\Pi$ virus in Hungary: sequence heterogeneity and mixed infections. FEMS Immun Med Microbiol 2003;35:153-7.

24 Bendinelli M, Pistello M, Maggi F, et al. Molecular properties, biology, and clinical implication of $\Pi$ virus, a recently identified widespread infectious agent of humans. Clin Microbiol Rev 2001;14:98-113. 